\title{
ANALISIS KETERSEDIAN AIR DAN PENGGUNAAN AIR (WATER BALANCE) UNTUK PENDUDUK KOTA KUPANG
}

\author{
Ivonia Isabela Raya ${ }^{1}$, Wilhelmus Bunganaen ${ }^{2}$, Rosmiyati A. Bella ${ }^{3}$ \\ Prodi Teknik Sipil, Fakultas Sains dan Teknik, Universitas Nusa Cendana \\ 1,2,3 Dosen Prodi Teknik Sipil, Fakultas Sains dan Teknik, Universitas Nusa Cendana \\ Jl. Adi Sucipto Penfui, Kota Kupang, Nusa Tenggara Timur \\ E-mail :elaraya2020@gmail.com, wilembunganaen@yahoo.co.id, qazeboo@yahoo.com
}

\begin{abstract}
ABSTRAK
Kota Kupang merupakan salah satu Kota di provinsi Nusa Tenggara Timur yang memiliki kondisi iklim yang kering dengan curah hujan tahunan sebesar $731 \mathrm{~mm} /$ tahun, sehingga dapat dikategorikan sebagai kota dengan curah hujan rendah (<1500 mm/tahun). Kondisi ini menyebabkan diperlukannya suatu analisis keseimbangan air. Penelitian ini dilakukan untuk mengetahui potensi, pemanfaatan air dan keseimbangan air di Kota Kupang. Metode yang digunakan dalam penelitian ini adalah metode kualitatif berupa analisis data yang diperoleh dari lapangan yaitu data koordinat dan elevasi lokasi studi dan metode kuantitatif berupa analisis hidrologi untuk analisis neraca air berdasarkan metode FJ Mock dan analisis penduduk menggunakan metode aritmatik. Selanjutnya pengumpulan data primer dilakukan melalui pengambilan titik koordinat dan dokumentasi di lapangan, sedangkan data sekunder yang dikumpulkan adalah data curah hujan dari BMKG, data embung dari BWS NT2, data mata air dan sumur bor dari P2AT dan data penduduk dari BPS Kota Kupang. Berdasarkan hasil perhitungan neraca air, total ketersediaan air (aktiva) di Kota Kupang sebesar 147.120.00 m²/tahun dan total pemanfaatan / kebutuhan air (pasiva) sebesar 129.120.000 $\mathrm{m}^{3} /$ tahun. Hal ini menunjukan bahwa di Kota Kupang terjadi surplus air. Namun di sisi lain, penelitian ini juga memperlihatkan adanya defisit air di tiga Kecamatan di Kota Kupang pada musim kemarau. Oleh karena itu perlu dilakukan pengolahan dan pemanfaatan air agar terjadi keseimbangan air pada musim hujan dan musim kemarau.
\end{abstract}

Kata kunci : Ketersediaan, Neraca Air Penggunaan

\section{PENDAHULUAN}

Ketersediaan air di dunia ini begitu melimpah, hampir $70 \%$ dari bumi adalah air namun yang dapat dikonsumsi oleh manusia untuk keperluan air minum sangatlah sedikit, dari total jumlah air yang ada, hanya $5 \%$ saja yang tersedia sebagai air minum, sedangkan sisanya adalah air laut (https://kelair.bppt.go.id). Ketersediaan air minum yang minim ini belum dapat memenuhi kebutuhan air penduduk yang setiap saat bertambah. Semakin meningkatnya populasi penduduk maka semakin meningkat pula kebutuhan akan air. Hal ini menimbulkan terjadinya kekurangan air yang berdampak pada ketidakseimbangan antara ketersediaan dan kebutuhan air. Ketidakseimbangan air memicu munculnya persoalan kekurangan air yang hampir selalu dialami di beberapa wilayah, termasuk Kota Kupang. Dilansir dari sebuah sumber menyatakan bahwa Kota Kupang mengalami krisis air bersih dan defisit air akibat kemarau panjang
(https://Republika.co.id). Kota Kupang memiliki beberapa potensi sumber air yang dikembangkan berupa 7 Daerah Aliran Sungai (Sungai Dendeng, Sungai Salak, Sungai Kolano, Sungai Alak, Sungai Oesapa Besar, Sungai Baumata dan Sungai Osmok), 11 embung potensial, 13 mata air serta 33 sumur bor (Balai Wilayah Sungai Nusa Tenggara II, P2AT Kota Kupang). Namun karena belum optimalnya pemanfaatan sumber daya air yang ada maka hingga saat ini masih terdapat kasus krisis air bersih pada musim kemarau. Selanjutnya hal ini juga disebabkan Kota Kupang memiliki iklim kering sedang yang ditandai dengan musim kemarau yang sangat panjang (April- November) dan musim hujan yang sangat pendek (Desember-Maret). Selain itu rata-rata temperatur udara minimum berkisar $20,1^{0}-24,5^{\circ} \mathrm{C}$ dan maksimum berkisar $29,9^{0}-35,2^{\circ} \mathrm{C}$, temperatur udara ratarata sekitar $27,5^{\circ} \mathrm{C}$, kelembapan udara antara $64 \%-90 \%$, dan rata-rata curah hujan 110 hari per tahun serta penyinaran matahari terendah 
sebesar $50 \%$ pada musim hujan dan penyinaran matahari tertinggi $98 \%$ pada musim kemarau (BPS Kota Kupang, 2018). Krisis air bersih dapat terjadi tidak hanya disebabkan oleh faktor iklim tetapi juga dipengaruhi oleh adanya ketidakseimbangan ketersediaan dan penggunaan air. Oleh karena itu perlu dilakukan penelitian "Analisis Keseimbangan Ketersediaan Air dan Penggunaan Air untuk Masyarakat Kota Kupang" dengan memanfaatkan seluruh potensi sumber daya air di Kota Kupang sehingga dapat diketahui apakah Kota Kupang mengalami kelebihan (surplus) atau kekurangan (defisit) air.

\section{TINJAUAN PUSTAKA}

\section{Siklus Hidrologi}

Siklus hidrologi adalah gerakan air laut menguap ke udara, yang kemudian jatuh ke permukaan tanah lagi sebagai hujan atau bentuk presipitasi lain, dan menimbulkan limpasan yang mengalir kembali ke laut. Siklus hidrologi merupakan proses kejadian air yang berlangsung secara kontinu sehingga menghasilkan air menjadi sumber daya alam yang terbaharui (renewable). Dalam siklus hidrologi ini terdapat beberapa proses yang saling terkait yaitu antara proses hujan (presipitation), penguapan (evaporation), transpirasi, infiltrasi, perkolasi, aliran limpasan (runoff), dan aliran bawah tanah. Dalam siklus hidrologi ini terdapat beberapa proses yang saling terkait yaitu antara proses hujan (presipitation), penguapan (evaporation), transpirasi, infiltrasi, perkolasi, aliran limpasan (runoff), dan aliran bawah tanah (suripin, 2003).

\section{Ketersediaan Sumber Daya Air (Aktiva)}

1. Air hujan adalah air yang berasal dari sublimasi uap air di udara yang dihasilkan oleh awan yang potensial, terkondensasi karena suhu rendah akan terbentuk butirbutir air dan jatuh karena gaya grafitasi sebagai titik-titik hujan (Asdak, 2010).

2. Air Permukaan

a. Sungai dalam siklus hidrologi, aliran sungai digolongkan sebagai aliran permukaan.

b. Embung adalah bangunan konservasi air berbentuk kolam untuk menampung air hujan dan air limpasan serta sumber air lainnya untuk mendukung usaha pertanian, perkebunan dan peternakan terutama pada saaat musim kemarau.

c. Mata Air (spring) adalah sumber air yang muncul dengan sendirinya ke permukaan dari dalam tanah.
3. Air Tanah Berdasarkan UU No. 7, Tahun 2004 Bab I Pasal 1 tentang Sumber Daya Air, dikatakan bahwa Air tanah adalah air yang terdapat dalam lapisan tanah atau batuan di bawah permukaan tanah.

\section{Analisis Proyeksi Penduduk}

1. Metode Aritmatik

$$
\mathrm{Pn}=\mathrm{Po}+(\mathrm{n} . \mathrm{q}) \mathrm{Po}
$$

2. Metode Geometrik

$$
P_{n}=P_{o}(1+r)^{n}
$$

2. Metode Eksponensial

$$
P_{n}=P_{o}(e)^{n \cdot q}
$$

$$
\begin{aligned}
& \text { Di mana : } \\
& \begin{aligned}
& \mathrm{P}_{\mathrm{n}}=\text { Jumlah penduduk pada tahun ke }-\mathrm{n} \\
& \mathrm{P}_{\mathrm{O}}= \text { Jumlah penduduk pada tahun dasar } \\
& \mathrm{r}= \text { Laju pertumbuhan penduduk } \\
& \mathrm{n}= \text { Jumlah interval } \\
& \mathrm{e}= \text { Nilai eksponensial yang besarnya } \\
& \text { adalah } 2,7182818 \\
& \mathrm{q}= \text { Perkembangan penduduk rata-rata }
\end{aligned}
\end{aligned}
$$

\section{Kebutuhan Sumber Daya Air (Pasiva)}

Tujuan pemeriksaan uji frekuensi adalah untuk mengetahui kebenaran antara hasil pengamatan dengan model distribusi yang diharapkan. atau yang memperoleh secara teoritis dan mengetahui hipotesa (diterima atau ditolak).

\section{a. Uji smirnov-kolmogorov}

Uji smirnov-kolmogorov sering juga disebut uji kecocokannon-parametik karena pengujiannya tidak menggunakan fungsi distribusi tertentu.

\section{b. Uji Chi-kudrat}

Uji chikuadrat dimaksudkan untuk menentukan apakah persamaan distribusi yang telah dipilih dapat mewakili distribusi statistik sampel data yang dianalisis.

\section{Waktu Konsentrasi}

1. Kebutuhan air untuk irigasi

Penggunaan air untuk irigasi yang dipergunakan dalam waktu satu tahun sehingga pengaruh lama tanaman dan prosentase (\%) intensitas tanaman harus diperhitungkan (Anonimus, 2011). Perhitungan penggunaan air untuk padi per tahun menggunakan persamaan :

Di mana:

$A=$ Pengunaan air irigasi dalam

$\mathrm{L}=$ Luas daerah irigasi ( $\mathrm{Ha}$ )

It = Intensitas tanaman dalam prosen (\%) musim/tahun 
$\mathrm{a}=$ Standar penggunaan air $(1 \mathrm{~L} / \operatorname{det} / \mathrm{ha})$ atau

A $=0,001 \mathrm{~m} / \operatorname{det} /$ ha $\times 3600 \times 24 \times 120$ hari / musim.

2. Kebutuhan air non irigasi

a. KebutuhanAir Bersih Rumah Tangga (Domestik)

Air yang diperlukan untuk rumah tangga yang diperoleh secara individu dari sumber air yang dibuat oleh masing masing rumah tangga seperti sumur dangkal, perpipaan atau hidran umum (Asdak, 2010).

b. Kebutuhan air perkotaan -komersial dan sosial (non domestik)

Untuk komersial dan sosial seperti: toko, gudang, bengkel, sekolah, rumah sakit, hotel dan sebagainya.

c. Kebutuhan air industri

Survei kebutuhan air industri diperlukan untuk menentukan rata-rata penggunaan air pada berbagai jenis industri tertentu.

\section{Analisis Neraca Air (Water Balance)}

1. Analisis neraca air dengan simulasi Mock

Dr. F.J. Mock (1973) memperkenalkan model sederhana simulasi keseimbangan air bulanan untuk aliran yang meliputi data hujan, evaporasi dan karakteristik hidrologi daerah pengaliran (Soemarto C. D., 1981).

2. Evapotranspirasi aktual (Ea)

Evapotranspirasi aktual dari Evaporasi potensial metode Penman (ETo). Hubungan antara evaporasi potensial dengan evapotranspirasi aktual dihitung dengan rumus:

$$
\begin{aligned}
\text { ETo } & =\mathrm{c} \times \mathrm{ETO}^{*} \\
\mathrm{ETO}^{*} & =\mathrm{W}(0.75 \mathrm{Rs}-\mathrm{Rn} 1)+(1-\mathrm{W}) \\
& (\text { ea-ed })
\end{aligned}
$$

Di mana:

$$
\begin{aligned}
& \text { Eto = Evaporasi potensial }(\mathrm{mm} / \mathrm{hari}) \\
& \text { c }=\text { Faktor koreksi } \\
& \text { ETo* = Evaporasi ( } \mathrm{mm} / \mathrm{hari}) \\
& \mathrm{W}=\text { Faktor yang berhubungan } \\
& \text { dengan suhu (t) dan elevasi } \\
& \text { daerah. } \\
& \text { Rs = Radiasi gelombang pendek, dalam } \\
& \text { satuan evaporasi ekivalen } \\
& \text { (mm/hari) } \\
& =(0.25+0.54 \mathrm{n} / \mathrm{N}) \mathrm{Ra}
\end{aligned}
$$

$$
\begin{aligned}
(\text { ea-ed })= & \begin{array}{l}
\text { Perbedaam tekanan uap jenuh } \\
\text { dengan tekanan uap yang } \\
\text { sebenarnya }
\end{array} \\
\text { ea } & \text { Eto }-\Delta \mathrm{E} \rightarrow(\mathrm{Ea}=\mathrm{Et}) \\
\Delta \mathrm{E} \quad= & \mathrm{ETo} \times(\mathrm{m} / 20) \times(18-\mathrm{n}) \rightarrow(\mathrm{E}= \\
& \Delta \mathrm{E})
\end{aligned}
$$

Di mana:

$$
\begin{aligned}
\mathrm{Ea}= & \text { Evapotranspirasi aktual }(\mathrm{mm} / \mathrm{hari}) \\
\mathrm{Et}= & \text { Evapotranspirasi terbatas } \\
& \text { (mm/hari) } \\
\mathrm{Eto}= & \text { Evaporasi Potensial metode } \\
& \text { Penman (mm/hari) } \\
\mathrm{M}= & \text { Prosentase lahan yang tertutup } \\
& \text { tanaman, ditaksir dari peta tata } \\
& \text { guna lahan } \\
\mathrm{m}= & 0 \text { untuk lahan dengan hutan lebat } \\
\mathrm{m}= & 0 \text { untuk lahan hutan sekunder } \\
& \text { pada akhir musim hujan dan } \\
& \text { bertambah } 10 \% \text { setiap bulan } \\
& \text { kering berikutnya } \\
\mathrm{m}= & 10-40 \% \text { untuk lahan tererosi } \\
\mathrm{m}= & 30-50 \% \text { untuk lahan pertanian } \\
& \text { yang diolah (misal: sawah, } \\
& \text { ladang) } \\
\mathrm{n}= & \text { Jumlah hari hujan dalam sebulan }
\end{aligned}
$$

3. Evapotranspirasi Terbatas (ET)

$$
\begin{aligned}
& \mathrm{ET}=\mathrm{Ep}-\mathrm{E} \\
& E=E p \times(m / 20) \times(18-n) \\
& \text { Di mana: } \\
& \text { ET = Evapotranspirasi terbatas }(\mathrm{mm}) \\
& \mathrm{Ep}=\text { Evapotranspirasi potensial }(\mathrm{mm}) \\
& \mathrm{E}=\text { Beda antara evapotranspirasi } \\
& \text { potensial dengan } \\
& \text { evapotranspirasi terbatas }(\mathrm{mm}) \text {. } \\
& \mathrm{M} \text { = Exposed surface (singkapan } \\
& \text { lahan (\%)). } m=0 \% \text {, untuk lahan } \\
& \text { dengan hutan lebat. } \\
& \mathrm{M}=0 \% \text {, untuk lahan dengan hutan } \\
& \text { sekunder pada akhir musim hujan } \\
& \text { dan bertambah } 10 \% \text { setiap bulan } \\
& \text { kering berikutnya. } \\
& \mathrm{m}=10 \%-40 \% \text {, untuk lahan yang } \\
& \text { tererosi. } \\
& \mathrm{m}=20 \%-50 \% \text {, untuk lahan } \\
& \text { pertanian yang diolah (sawah, } \\
& \text { ladang) } \\
& \mathrm{n} \quad=\text { Jumlah hari hujan dalam sebulan }
\end{aligned}
$$

,


Ivonia Isabela Raya*, Wilhelmus Bunganaen², dan Rosmiyati A. Bella

di 6 kecamatan yakni Kecamatan Alak, Kota Lama, Kelapa Lima, Kota Raja, Oebobo dan Maulafa. Waktu penelitian dilakukan dari bulan Juni 2018 sampai Agustus 2019.

2. Sumber Data

Data primer dalam penelitian ini adalah data koordinat dan dokumentasi 7 DAS yaitu DAS Dendeng, Salak, Kolano, Osmok, Oesapa Besar, Baumata, Pasir Panjang serta data koordinat dan dokumentasi dari 11 embung yakni embung Manulai II, Koekila, Fatufutu, Kibiblian, Nunu'sa, Batu Gosok, Hoenebab, Klubiblian, Bisiti, Pohonitas, dan Kiumese. Sedangkan data sekunder dalam penelitian ini diperoleh dari instansi - instansi, buku literatur, dokumendokumen dan arsip yang telah ada berupa data curah hujan harian selama 20 tahun dari tahun 1998 -2017, data luas DAS, data embung, data sumur bor, data mata air serta data jumlah penduduk dan data fasilitas penduduk di Kota Kupang.

3. Teknik Pengumpulan Data dan Teknik Analisa Data

Teknik pengumpilan data yang digunakan adalah studi pustaka berupa pengumpulan data yang diperoleh dari dokumen, arsip atau buku-buku yang berkaitan dengan penelitian ini serta teknik dokumentasi berupa pengumpulan data yang diperoleh dengan cara pengambilan dokumentasi/gambar pada lokasi penelitian. Berdasarkan data yang didapat berupa data primer dan data sekunder maka dilakukan analisa data dengan langkah - langkah sebagai berikut :

Analisis proyeksi penduduk dilakukan untuk mengetahui jumlah penduduk untuk 20 tahun mendatang. Analisis ini dilakukan dengan menggunakan tiga metode yakni metode arithmatik $(P n=P o+(n . q) P o)$, Geometrik $\left(P_{n}=P_{0}(1+r)^{n}\right)$ dan Eksponensial $\left(P_{n}=P_{o}(e)^{n . q}\right)$. Dari ketiga metode tersebut, metode yang memiliki nilai standar deviasi mendekati satu akan digunakan hasilnya untuk analisis proyeksi kebutuhan air.

Analisis proyeksi kebutuhan air bersih dilakukan guna mengetahui kebutuhan air bersih yang di perlukan oleh penduduk. Dalam menganalisis kebutuhan air penduduk dilakukan perhitungan kebutuhan air domestik untuk keperluan rumah tangga yang dihitung berdasarkan jumlah penduduk, tingkat pertumbuhan, kebutuhan air perkapita dan proyeksi waktu air akan digunakan. Kemudian dilanjutkan dengan melakukan perhitungan kebutuhan air non domestik untuk keperluan di dalam rumah, di luar rumah dan keran umum seperti kebutuhan air untuk instansi/ kantor, untuk sekolah, untuk tempat ibadah, dll. Besarnya kebutuhan air bersih dihitung dengan menggunakan acuan Dirjen Cipta Karya, 1996.

Analisis ketersedian air dilakukan dengan menghitung debit air permukaan yang terdiri atas analisis curah hujan, analisis air permukaan dan analisis air tanah selanjutnya dilakukan analisis neraca air (water balance) dengan simulsi Mock.

\section{HASIL DAN PEMBAHASAN \\ Analisis Kebutuhan Sumber Daya Air (Pasiva) di Kota Kupang.}

1. Proyeksi pertumbuhan penduduk

Untuk menganalisis proyeksi kebutuhan air untuk beberapa tahun ke depan maka terlebih dahulu dilakukan proyeksi pertumbuhan penduduk dengan metode Aritmatik, metode Geometrik dan metode Eksponensial.

Jumlah penduduk yang digunakan dalam perhitungan kebutuhan air bersih adalah hasil proyeksi penduduk dari metode Aritmatik dikarenakan metode aritmatik memiliki standar deviasi yang terkecil.

2. Proyeksi kebutuhan air bersih

Kebutuhan air bersih untuk penduduk dibedakan menjadi dua yakni kebutuhan air sektor domestik dan non domestik. Kebutuhan air sekor domestik mencakupi perhitungan kebutuhan air saluran rumah tangga dan hidran umum yang dihitung menggunakan jumlah penduduk berdasarkan metode aritmatik, sedangkan kebutuhan air sektor non domestik mencakupi perhitungan kebutuhan air gereja, masjid, pasar, sekolah, rumah sakit, dan puskesmas.

Tabel 2 Proyeksi Kebutuhan Air Bersih di Kota Kupang Sampai Tahun 2037

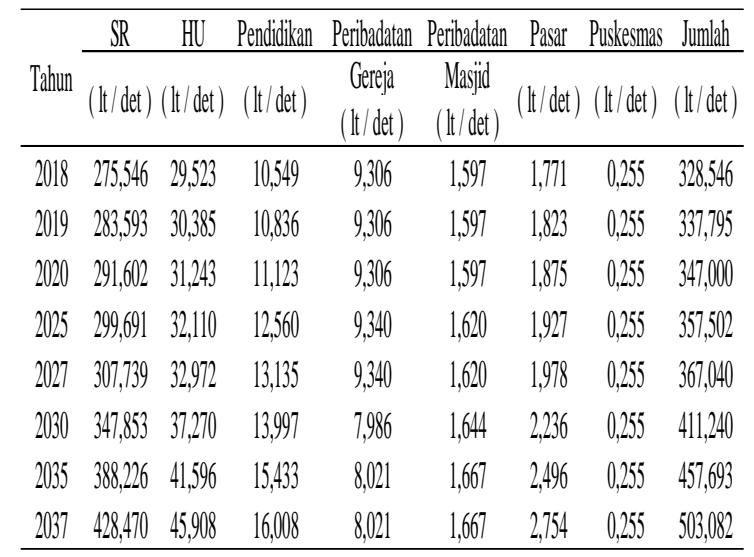


Berdasarkan proyeksi kebutuhan air pada Tabel 2, berikut ini diproyeksikan kebutuhan air bersih berdasarkan kebutuhan normal, hari

maksimum dan jam puncak yang dapat dilihat pada Tabel 3. Untuk mendapatkan nilai hari maksimum diperoleh dengan mengalikan jumlah total kebutuhan normal dengan faktor fluktuasi 1,15 (Lampiran 15). Untuk nilai jam puncak diperoleh dari mengalikan jumlah total kebutuhan normal dengan faktor fluktuasi 1,75.

Tabel 3 Proyeksi Kebutuhan Air Bersih Berdasarkan Kondisi Normal, Hari Maksimum, dan Jam Puncak Sampai Tahun 2037

\begin{tabular}{|c|c|c|c|c|c|c|c|}
\hline & Faltor & 2018 & 2019 & 2020 & $2025 \quad 2027$ & 2030 & $2035 \quad 2037$ \\
\hline Nomal & 1 & 388,546 & 337,955 & 37,000 & $357,002 \quad 367,040$ & 411,240 & $457,0935503,082$ \\
\hline (ttdett) & 1,15 & 377,828 & 388,464 & 399,60 & $411,128,42,006$ & 472,927 & $526,347578,544$ \\
\hline $\begin{array}{l}\mathbb{P} \\
(\text { Itdet })\end{array}$ & 1,75 & 574,966 & 59,141 & 607,50 & $625,62964,320$ & 719,671 & $800,633800,393$ \\
\hline
\end{tabular}

Setelah melakukan perhitungan proyeksi penduduk dan proyeksi kebutuhan air bersih, maka selanjutnya dilakukan perhitungan ketersediaan sumber daya air (aktiva) untuk mengetahui berapa besarnya ketersediaan air di Kota Kupang.

\section{Analisis Ketersediaan Sumber Daya Air (Aktiva) di Kota Kupang}

Ketersediaan sumber daya air pada penelitian di Kota Kupang ini terbagi menjadi 3 yaitu: air hujan, air permukaan, air tanah.

1. Air Hujan

Dalam penelitian ini, data hujan diambil dari Stasiun Klimatologi Lasiana Kupang karena dari 3 Stasiun Klimatologi yang aktif, Stasiun Klimatologi Lasiana Kupang memiliki data yang paling lengkap yakni dari tahun 1998 - 2017. Hasil rekapitulasi curah hujan harian maksimum pada stasiun Klimatologi Lasiana dapat dilihat pada Tabel 4.

Tabel 4 Data Curah Hujan Harian Maksimum Pada Stasiun Klimatologi Lasiana

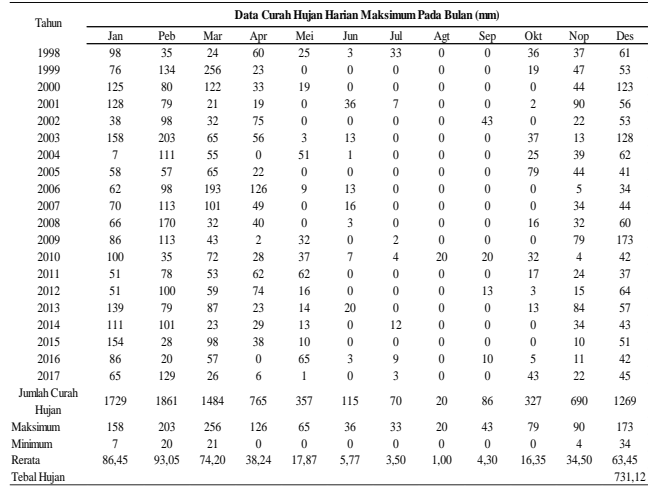

Berdasarkan data pada Tabel 4 terlihat bahwa potensi tebal curah hujan di Kota Kupang adalah sebesar 731,12 mm/tahun,

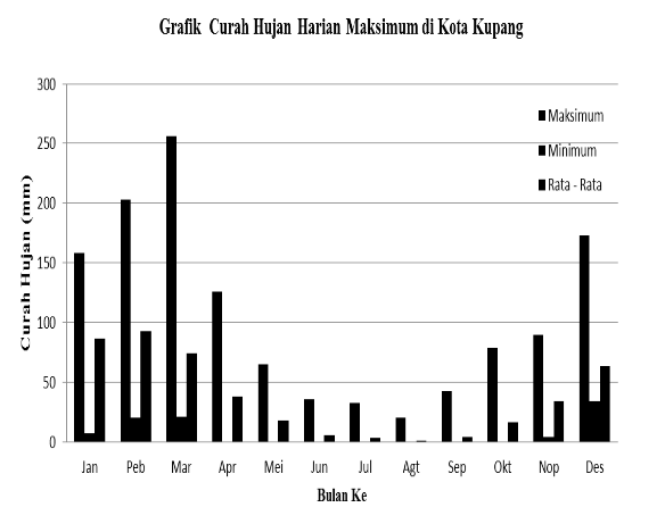

sehingga curah hujan rata-rata yang terjadi di Kota Kupang termasuk dalam kelas rendah $(<1.500 \mathrm{~mm} / \mathrm{tahun})$. Untuk lebih jelas data dari Tabel 4 dapat dilihat pada Gambar 1. Dari gambar tersebut terlihat bahwa potensi hujan terendah terjadi pada bulan Agustus dengan potensi sebesar $1.00 \mathrm{~mm} /$ tahun dan potensi terbesar terjadi pada bulan Februari sebesar 93,05 mm/tahun.

\section{Gambar 1 Curah Hujan Maksimum Bulanan di Kota Kupang}

2. Air permukaan

a. Sungai

Untuk menganalisa debit sungai, pada penelitian ini digunakan pendekatan dan asumsi untuk mengubah data hujan menjadi data potensi air permukaan / sungai dengan menggunakan metode F.J. Mock. Rekapitulasi hasil perhitungan debit 7 DAS di Kota Kupang dapat dilihat pada Tabel 5.

Tabel 5 Analisis Neraca Air Untuk DAS di Kota Kupang 
Ivonia Isabela Raya*, Wilhelmus Bunganaen², dan Rosmiyati A. Bella

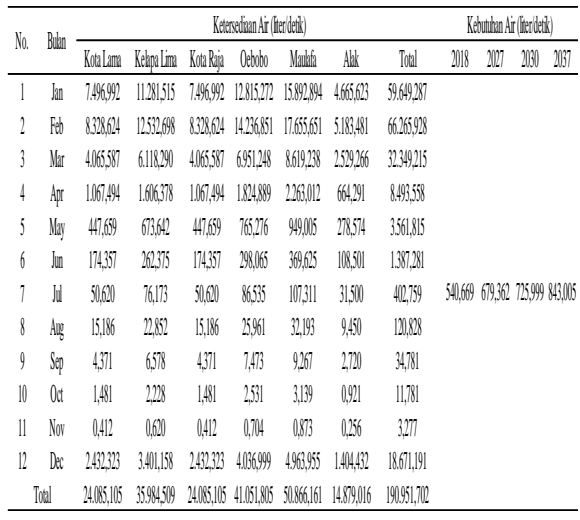

Berdasarkan Tabel 5 menunjukkan bahwa pada masing-masing kecamatan di Kota Kupang memiliki ketersediaan debit andalan sungai yang mencukupi di bulan Desember hingga Maret dengan ketersediaan air tertinggi terjadi pada bulan Februari untuk semua kecamatan. Namun setelah musim hujan, terjadi penurunan yang cukup drastis pada seluruh DAS di wilayah Kota Kupang. Potensi air sungai terbesar terletak pada Kecamatan Maulafa sebesar $50.866,091 \mathrm{l} /$ detik, sedangkan potensi terendah terjadi pada Kecamatan Alak dengan potensi air sungai sebesar $14.879,016$ l/detik.

b. Embung

Berdasarkan hasil survei lapangan di Kota Kupang terdapat 11 embung yang terletak di Kecamatan Alak. Dalam menganalisis besarnya debit air embung dilakukan dengan menggunakan metode F.J. Mock. Rekapitulasi hasil perhitungan debit 11 embung di Kota Kupang dapat dilihat pada Tabel 6.

Tabel 6 Rekapitulasi Hasil Perhitungan Debit Andalan 11 Embung di Kota Kupang

\begin{tabular}{|c|c|c|c|c|c|c|c|c|c|c|c|c|c|}
\hline \multirow{2}{*}{\multicolumn{2}{|c|}{ Embruge }} & \multicolumn{11}{|c|}{ 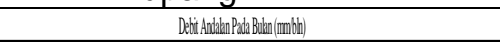 } & \multirow[b]{2}{*}{ Dis } \\
\hline & & In & Peto & $V_{\text {arr }}$ & Apr & Mei & lair & 情 & Ag & Sip & $0 \mathrm{dit}$ & Inp & \\
\hline & Embung Hoentedad & 0,278 & 0,318 & 0,153 & 0,040 & 00,117 & 0,006 & $0,0,0$ & 0,01 & $10,0,00$ & $0 \quad 0,000$ & $0,0,000$ & 0,097 \\
\hline & Embung Kibblilina & 0.57 & 0,619 & 0,318 & 0,080 & 0 0,1,33 & 0,013 & 0,04 & 0,001 & 1] 0,000 & 00,000 & $0,0,00$ & $0,0,15$ \\
\hline & Embung Bisii & 0,61 & 0,733 & 0,300 & 0,093 & 30,039 & 0,015 & $0,0 \mathrm{OA}$ & 0,01 & 0,00 & 00,000 & 0,000 & 0,288 \\
\hline & Embun POhonoings & 0,740 & 0,82 & 0,40 & 0.116 & 60,04 & 0,017 & 0,002 & $0,0,02$ & $20,0,00$ & $00,0,00$ & $0,0,00$ & 0.57 \\
\hline & Enbung Kinnsere & 0,899 & 0,91 & 0,464 & 0,120 & $00,0,50$ & 0,020 & 0,060 & $0,0,2$ & $2 \quad 0,0,00$ & 00,000 & 0,000 & 0,205 \\
\hline & 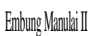 & 2320 & 2.576 & 1,29 & 0,32 & 20,139 & 0,054 & 0,016 & 0,055 & $5 \quad 0,001$ & $10,0,000$ & $0,0,00$ & 0,810 \\
\hline & Embung Kodidia & 0,41 & 0,833 & 0,48 & 0,116 & $60,0,4$ & 0,17 & 0,002 & $0,0,0$ & $2 \quad 0,0,00$ & 00,000 & 0,000 & 01,258 \\
\hline & Embong Fadututu & 2,801 & 2,312 & 1,14 & 0.28 & 80,125 & 0,49 & 0,014 & $0,0 \mathrm{AH}$ & $4 \quad 0,01$ & 110,000 & $0,0,00$ & 0,723 \\
\hline & Embung Krodilian & 2,46 & 2,602 & 1,288 & 0,34 & 40,14 & 0,066 & 0,016 & $0,0,0$ & $5 \quad 0,001$ & 110,000 & $0,0,00$ & $0,0,82$ \\
\hline & Enbung Vhan'sa & 0,70 & 0,82 & 0,407 & 0,116 & $60,0,4$ & 0,17 & $0,0 \mathrm{Di}$ & $0,0,0$. & $2 \quad 0,0,00$ & 00,000 & 0,000 & 0,057 \\
\hline & Emblung Badu Cososk & 0,000 & 0,03 & 0,011 & $0,0,03$ & 30,001 & 0,000 & 0,00 & $0,0,0$ & $0,0,00$ & 00,000 & $0,0,00$ & 0,007 \\
\hline & Total & 1,034 & 1,148 & 0,50 & 0,148 & 80,062 & 0,04 & 0,00 & 7 0,000 & $2 \quad 0,001$ & $10,0,000$ & 0,000 & $0,0,61$ \\
\hline
\end{tabular}

Kota Kupang dapat dilihat pada Gambar 2.

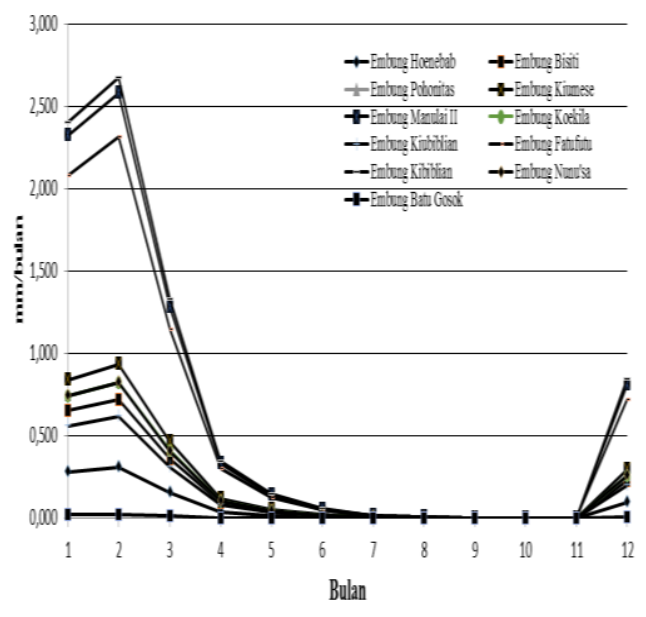

Gambar 2 Grafik nilai rata-rata debit embung andalan di Kota Kupang Berdasarkan Gambar 2 nilai debit tertinggi terjadi di Embung Kibiblian berada pada bulan Februari sebesar $0,027 \mathrm{~m}^{3} / \mathrm{dtk}$. Sedangkan nilai debit terendah untuk tiap Embung berada pada bulan Juni - Oktober dengan nilai rata - rata debit sebesar 0,000 $\mathrm{m}^{3} / \mathrm{dtk}$.Selanjutnya untuk analisis perhitungan volume tampungan embung secara keseluruhan perhitungannya menggunakan rumus (P - I - Eto).

c. Mata Air

Mata air merupakan salah satu sumber air yang penting di Kota Kupang. Data hasil estimasi debit mata air di Kota Kupang dapat dilihat pada dapat dilihat dalam Tabel 7.

Tabel 7 Data Mata Air yang Terdapat di Kota Kupang

\begin{tabular}{|c|c|c|c|c|c|}
\hline \multirow{3}{*}{ No } & \multirow{3}{*}{ Nama Mata Air } & \multicolumn{3}{|c|}{ Estimas Debit } & \multirow[b]{2}{*}{$10^{6} \mathrm{~m}^{3}$} \\
\hline & & Debit Musim Hujan (Vdt) & Debii Kemarau Hujan (Vdt) & Ratala - rata (Vit) & \\
\hline & & \multicolumn{4}{|c|}{ Kecammanan Maubla } \\
\hline 1 & M.A 0epura & 118,00 & 25,00 & 71,50 & 0,19 \\
\hline 2 & M.A Kollua & 35,50 & 15,00 & 25,25 & 0,07 \\
\hline 3 & M.A Haukoto & 17,80 & 1,00 & 9,40 & 0,03 \\
\hline 4 & M.A Oetona & 4,22 & 4,00 & 4,11 & 0,01 \\
\hline 5 & M. A Kali Fatukoa & 12,02 & 1,00 & 6,51 & 0,02 \\
\hline \multirow[t]{3}{*}{6} & M. A Air Lobang & 2,80 & 15,00 & 8,90 & 0,02 \\
\hline & Total Debit & 190,34 & 61,00 & 125,67 & 0,34 \\
\hline & & \multicolumn{4}{|c|}{ Kecamatan Kota Raja } \\
\hline & M. A Dendeng & 20,30 & 10,00 & 15,15 & 0,04 \\
\hline & M. A Amrmesi & 120,50 & 20,00 & 70,25 & 0,19 \\
\hline 3 & M. A L abat & 323,00 & 20,00 & 171,50 & 0,46 \\
\hline & M. A Air Nona & 110,00 & 10,00 & 60,00 & 0,16 \\
\hline & Total Debit & 573,80 & 60,00 & 316,90 & 0.85 \\
\hline & & \multicolumn{4}{|c|}{ Kecamatan Alak } \\
\hline & M. A Sagu II & 174,88 & 35,00 & 104,94 & 0,28 \\
\hline & M. A SaguI & 150,00 & 30,00 & 90,00 & 0,24 \\
\hline & Total Debit & 324,88 & 65,00 & 194,94 & 0,52 \\
\hline & & \multicolumn{4}{|c|}{ Kecamtan Kota Lama } \\
\hline & M. A 0eba & 261,00 & 40,00 & 150,50 & 0,40 \\
\hline & Total Debit & 261,00 & 40,00 & 150,50 & 0,40 \\
\hline & & \multicolumn{4}{|c|}{ Kecammatan Kelapa Lima } \\
\hline & & \multicolumn{4}{|c|}{ Kecamanan Oebobo } \\
\hline
\end{tabular}

Berdasarkan Tabel 7 dapat dilihat pada Kecamatan Oebobo dan Kelapa Lima tidak 
memiliki sumber Mata Air. Ketersediaan air pada mata air terbesar terdapat pada mata air di Kecamatan Kota Raja dengan estimasi debit sebesar 316,90 l/dtk dan ketersediaan air terkecil berada pada Kecamatan Maulafa dengan estimasi debit sebesar 125,67 l/dtk. Besarnya nilai debit rata - rata pada mata air di Kota Kupang ditabulasikan dalam Gambar 3.

Debit Mata Air di Kota Kupang

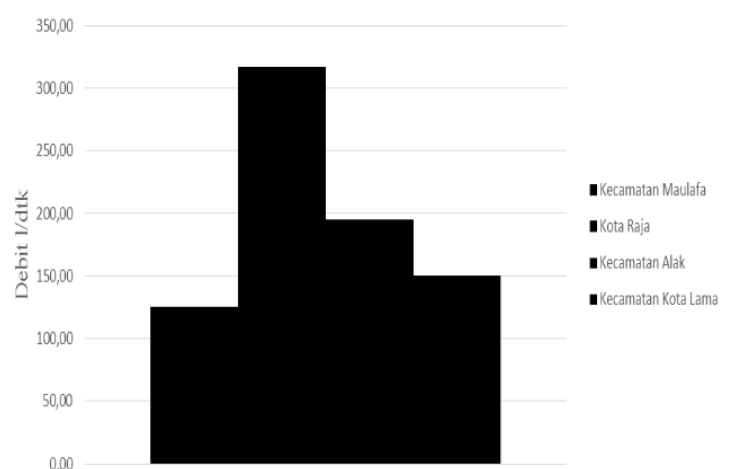

Gambar 3 Grafik Debit Mata Air yang

Tersebar pada Setiap Kecamatan di Kota Kupang

d. Air tanah

1. Sumur gali.

Menurut Laporan Akhir Penelitian Potensi Pengembangan Pengelolan dan Zonasi Air tanah di Kota Kupang (2007), di daerah Kota Kupang dan sekitarnya terdapat lebih dari 6.000 sumur gali dan dari jumlah tersebut telah

didata 3100 sumur gali. Sebaran sumur gali yang paling banyak terdapat di daerah

Maulafa hingga Oebufu dan Pasir Panjang hingga Oesapa, di mana di daerah

ini

hampir setiap 3-4 rumah memiliki satu buah sumur gali. Sumur gali juga banyak

terdapat di daerah Oebobo, Sikumana, Oetona, Labat, Oepura, Naikoten, Tofa, Bakunase-Manulai hingga Tabun Kedalaman sumur gali bervariasi, sumur terdangkal dengan kedalaman 1,2-2 meter terdapat di daerah Oesapa-Pasir Panjang dan Airmata sampai sumur terdalam yaitu kedalaman 42 meter, 48 meter didaerah Liliba. Umumnya sumur gali dimanfaatkan untuk kebutuhan rumah tangga, setiap sumur gali digunakan maksimal oleh 10-15 KK, yakni daerah Naimata dan Liliba (Adoe, 2008).

2. Sumur bor.

Untuk sumur bor di Kota Kupang terdapat 11 buah sumur bor yang dikelola oleh Proyek Pengembangan
Air Tanah (P2AT) Kota Kupang, 13 buah sumur bor yang dikelola oleh Perusahaan Daerah Air Minum (PDAM) Kota Kupang dan 9 sumur bor lainnya dikelola oleh instansi pemerintah, pendidikan, seminari, swasta dan perorangan. Potensi ketersediaan air pada sumur bor terbesar terdapat pada Kecamatan Kelapa Lima sebesar 57,13 I/detik dan potensi terkecil terletak pada Kecamatan Kota Lama sebesar 4,00 1/detik. Data Sumur Bor di Kota Kupang ditampilkan pada Tabel 8.

Tabel 8 Data Sumur Bor di Kota Kupang

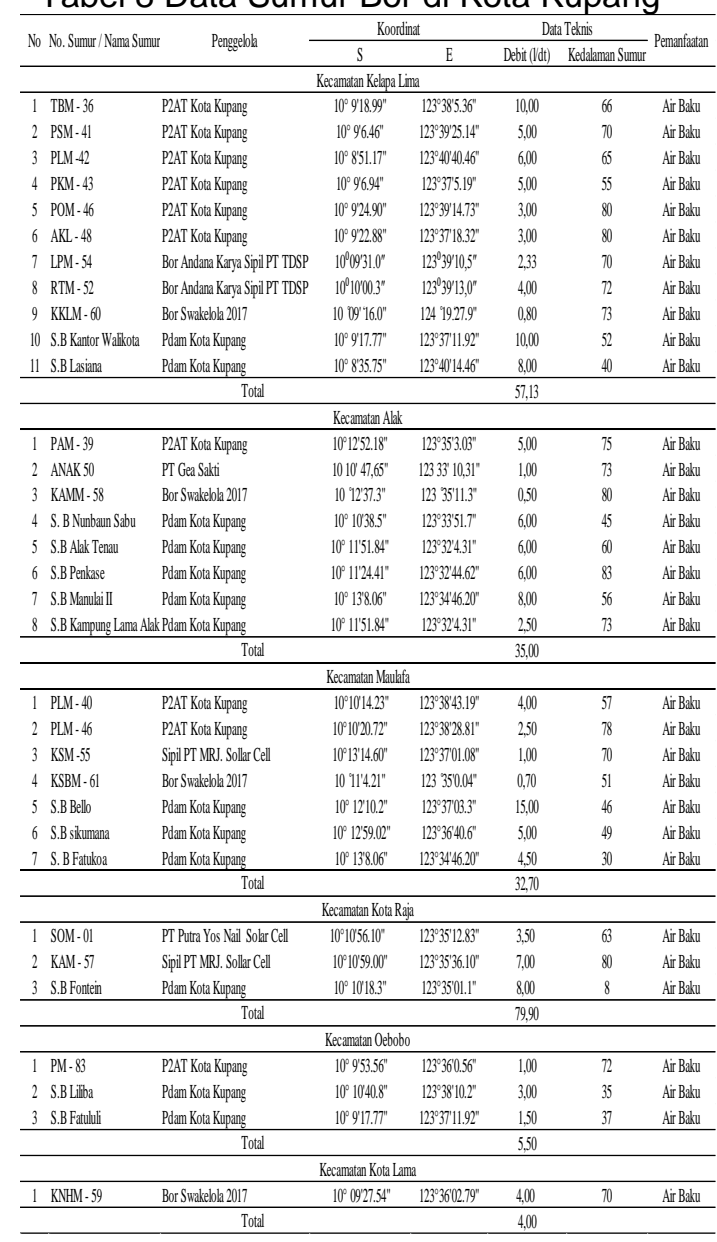

\section{Keseimbangan Air (Water Balance) di Kota Kupang}

Berdasarkan perhitungan ketersediaan air di Kota Kupang, selanjutnya akan dilakukan analisis keseimbangan air (Water Balance) berdasarkan hasil rekapan tiap - tiap sumber air di masing - masing kecamatan. Berikut ini merupakan rekapitulasi dari hasil analisis dan perhitungan data, khusus untuk hasil perhitungan ketersediaan sumber daya air (Aktiva) diasumsikan sebesar $25 \%$ dari hasil perhitungan untuk mencapai kondisi rill di lapangan dikarenakan faktor albedo evapotranspirasi $25 \%(0.25)$ oleh karena itu 
Ivonia Isabela Raya*, Wilhelmus Bunganaen², dan Rosmiyati A. Bella

diasumsi bahwa hasil yang telah diperoleh untuk mencapai kondisi rill tersebut telah dikalikan dengan $25 \%(0,25)$ neraca air untuk 6 kecamatan di Kota Kupang dapat dilihat pada Tabel 9.

Tabel 9 Rekapitulasi Perhitungan Neraca Air 6 Kecamatan di Kota Kupang

\begin{tabular}{|c|c|c|c|c|c|c|c|c|c|c|c|}
\hline \multirow{2}{*}{ To Keermitan } & \multirow{2}{*}{\multicolumn{2}{|c|}{ 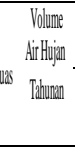 }} & \multicolumn{3}{|c|}{ Air Pramlanan } & \multirow{2}{*}{\multicolumn{2}{|c|}{$\begin{array}{c}\text { Totol } \\
\text { Potenis } \\
\text { SDA }\end{array}$}} & \multicolumn{2}{|c|}{ 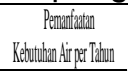 } & \multirow{2}{*}{ 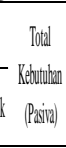 } & \multirow[b]{2}{*}{ leraxair } \\
\hline & & & Sungad & $\begin{array}{l}\text { Celunganan } \\
\text { (embung) }\end{array}$ & & & & Donsilik & NonDonsitili & & \\
\hline & $\mathrm{km}^{2}$ & $10^{6} m^{3}$ & $10^{6} \mathrm{~m}^{3}$ & $100^{3} m^{3}$ & $11^{6} \mathrm{~m}^{3}$ & $11^{6} \mathrm{~m}^{3}$ & $10 \mathrm{~m}^{3}$ & $10^{6} \mathrm{~m}^{3}$ & $10^{6} \mathrm{~m}^{3}$ & $10^{6} \mathrm{~m}^{3}$ & $10^{6} \mathrm{~m}^{3}$ \\
\hline$a b$ & i & $d$ & e & f & : & h & $I=e+f+g t h$ & h $\mathrm{j}$ & k & $1=j+\mathrm{k}$ & $m=[\cdot]$ \\
\hline 1 能 & 86,9 & 138,74 & 9,78 & 19,95 & 0,13 & 0.28 & 30,13 & 13,84 & $3, \#$ & 17,28 & 12855 \\
\hline 2 Moulata & 54,00 & 87,48 & 33,2 & 0,00 & 0,08 & 0,26 & 33,6 & 17,31 & 4,29 & 21,00 & 12,16 \\
\hline 3 Oelobo & $1,1,2$ & 2270 & 2697 & 0,0 & 0,00 & 0,4 & 27,01 & 21,91 & 5,16 & 27,07 & $\cdot 0,6$ \\
\hline 4 KotaRRiga & 6,10 & 9,7 & 15,22 & 0,0 & 0,21 & 0,15 & 16,18 & 11,83 & 2.68 & 21,60 & 5,42 \\
\hline 5 Kelpa Lima & & 3998 & 2,64 & 0,00 & 0,00 & 0,55 & 24,0 & 17,66 & 4,6 & 27,07 & .288 \\
\hline 6 Kotalena & 312 & 5,14 & 15,2 & 0,0 & 0,10 & 0,03 & 15,95 & 7,45 & 1,77 & $\mid 4,5]$ & $1,1,5$ \\
\hline Total & 18027 & 287,78 & 125,45 & 19,5 & 0,52 & 1.20 & $17,1,2$ & 90,00 & $21,1,0$ & 129,12 & 18,01 \\
\hline
\end{tabular}

Berdasarkan hasil pada Tabel 9 untuk kondisi secara umum, kecamatan Oebobo, Kota Raja dan Kelapa Lima mengalami kekurangan air dikarenakan kebutuhan air di ketiga Kecamatan tersebut lebih besar di bandingkan potensi sumber daya air yang dimiliki. Total ketersediaan air (Aktiva) di 6 kecamatan sebesar $147.120 .000 \mathrm{~m}^{3} /$ tahun dan total pemanfaatan / kebutuhan air (Pasiva) sebesar $129.120 .000 \mathrm{~m}^{3} /$ tahun. Ketersediaan air di 3 kecamatan sudah mencukupi untuk satu tahun namun di kecamatan Oebobo, Kota Raja dan Kelapa Lima terjadi defisit atau kekurangan air karena pemanfaatan air yang lebih besar dari ketersediaan air. Untuk neraca air di Kota Kupang dapat dilihat dalam Tabel 10.

Tabel 10 Rekapitulasi Perhitungan Neraca Air 6 kecamatan di Kota Kupang

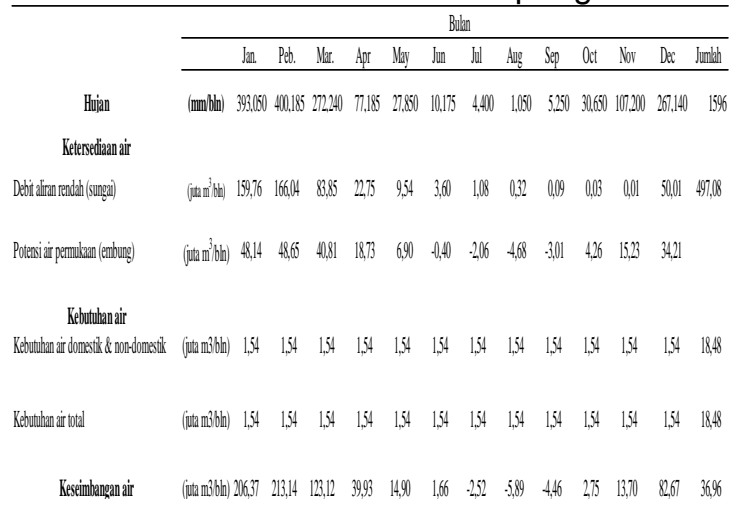

Pada Tabel 10 menunjukkan bahwa pada bulan Juli - September terjadi defisit air. Pada bulan Mei - November, Kota Kupang mengalami musim kemarau yang mengakibatkan penurunan ketersediaan air di daratan. Namun sebaliknya pada bulan Desember - April, air hujan yang turun menyebabkan volume air yang tertampung di cekungan tanah (embung) dan air yang mengalir di alur sungai menjadi cukup besar di sisi lain kebutuhan air total maksimum di Kota Kupang bersifat konstan yaitu sebesar 1,54 juta $\mathrm{m}^{3} / \mathrm{bln}$. Dengan demikian ketersediaan air di Kota Kupang pada bulan Oktober - Juni menjadi surplus.

\section{PENUTUP}

\section{Kesimpulan}

1. Proyeksi kebutuhan air bersih masyarakat Kota Kupang hingga tahun 2037 sebesar $834,005 \mathrm{l} / \mathrm{detik}$.

2. Potensi ketersediaan sumber daya air (aktiva) untuk 7 DAS di Kota Kupang sebesar 190.951,702 l/detik.

3. Potensi ketersediaan air pada 13 mata air yang terdapat di kecamatan Alak, Maulafa, Kota Raja dan Kota Lama sebesar 788,010 l/detik.

4. Untuk potensi sumber air cekungan (embung) di Kota kupang, terdapat 11 embung yang hanya terdapat di Kecamatan Alak dengan potensi air sebesar 36.927,189 I/detik.

5. Untuk air tanah terdapat 2 jenis air tanah yakni sumur gali dan sumur bor. Terdapat \pm 6.000 buah sumur gali milik warga yang tersebar di Kota Kupang yang airnya digunakan sebagai sumber air baku, sedangkan untuk sumur bor terdapat 33 buah sumur yang tersebar pada 6 kecamatan di Kota Kupang, dengan ketersediaan air sebesar 214,23 l/detik.

6. Berdasarkan hasil perhitungan neraca air di Kota Kupang, pada bulan Desember April terjadi surplus air dengan rata - rata sebesar 133,05 $\mathrm{m}^{3}$ sedangkan pada bulan Juli - September Kota Kupang mengalami kekurangan (defisit) air dengan rata -rata sebesar $-4,29 \mathrm{~m}^{3}$.

\section{Saran}

1. Perlu dilakukan penelitian yang lebih detail terhadap jumlah dan pemanfaatan sumur gali di Kota Kupang.

2. Luas DAS yang digunakan sebaiknya dihitung dengan menggunakan program GIS agar luas DAS yang di tinjau pada setiap kecamatan lebih akurat.

3. Perlu dilakukan penambahan sumber data dari BPS mengenai fasilitas industri di masing - masing kecamatan agar penelitian kebutuhan dan pemanfaatan air lebih akurat untuk tiap - tiap kecamatan.

4. Perlu dibangun kolam - kolam retensi.

5. Perlu adanya stasiun - stasiun hujan di setiap kecamatan agar data curah hujan hujan yang digunakan dapat mewakili seluruh persentase ketersediaan air hujan di Kota Kupang. 
DAFTAR PUSTAKA

Anonimus. (2011). Studi Alternatif Sistim

Pengembangan Sumber Air Baku di Daerah Kering Pulau - pulau Kecil

NTT. Kupang: PT. Jasakons Putra Utama Konsultan Teknik.

Asdak, C. (2010). Hidrologi dan Pengelolaan Daerah Aliran Sungai. Yogyakarta: Gadjah Mada University.

https://kelair.bppt.go.id. (n.d.). Retrieved from https://kelair.bppt.go.

https://Republika.co.id. (n.d.). Retrieved from https://Republika.co.id

Soemarto, C. D. (1981). Hidrologi Teknik. Surabaya: Usaha Nasional.

suripin. (2003). Sistem Drainase Kota Yang Berkelanjutan . Yogyakarta: Andy. 